\title{
Changes in left ventricular ejection fraction and coronary flow reserve after coronary microembolization
}

Jianying Ma, Juying Qian, Junbo Ge, Xin Zeng, Aijun Sun, Shufu Chang, Zhangwei Chen, Yunzeng Zou

Department of Cardiology, Zhongshan Hospital, Fudan University, Shanghai Institute of Cardiovascular Disease, Shanghai, China

Submitted: 27 August 2010

Accepted: 7 December 2010

Arch Med Sci 2012; 8, 1: 63-69

DOI: $10.5114 /$ aoms.2012.27283

Copyright $\odot 2012$ Termedia \& Banach

\section{Abstract}

Introduction: Although coronary microembolization (CME) is a frequent phenomenon in patients undergoing percutaneous coronary intervention, few data are available on the changes in left ventricular ejection fraction (LVEF) and coronary flow reserve (CFR) after CME.

Material and methods: In this study, six miniature swine of either sex (body weight $21-25 \mathrm{~kg}$ ) were used to prepare a CME model. After coronary angiography, $1.2 \times 10^{5}$ microspheres $(42 \mu \mathrm{m})$ were selectively infused into the left anterior descending artery via an infusion catheter. Left ventricular ejection fraction was evaluated using transthoracic echocardiography; myocardial blood flow was measured using coloured microspheres; and CFR and coronary pressure were measured using Doppler and a pressure wire.

Results: Left ventricular ejection fraction was $0.77 \pm 0.08$ at baseline, $0.69 \pm 0.08$ at $2 \mathrm{~h}, 0.68 \pm 0.08$ at $6 \mathrm{~h}$, and $0.76 \pm 0.06$ at 1 week $(2 \mathrm{~h}$ vs. baseline $p<0.05$; $6 \mathrm{~h}$ vs. baseline $p<0.01$ ). After CME, left ventricular end systolic volume (LVESV) and end diastolic volume (LVEDV) were significant larger 1 week later $(p<0.01$ for both), while CFR was significantly reduced at 6 h ( $1.24 \pm 0.10$ at 6 h vs. 1.77 \pm 0.30 at baseline, $p<0.01$ ) and myocardial blood flow remained unchanged. Serum ET-1 level was significantly higher only at $6 \mathrm{~h}$ after CME ( $6 \mathrm{~h}$ vs. baseline $p<0.05)$

Conclusions: Reduction of CFR and LVEF is significant at $6 \mathrm{~h}$ after CME and recovers 1 week later with left ventricular dilation.

Key words: coronary artery, microembolization, remodelling, left ventricular ejection fraction.

\section{Introduction}

Coronary microembolization (CME), which is frequent in patients undergoing percutaneous coronary intervention $(\mathrm{PCI})$ [1], potentially leads to perfusion-contraction mismatch, inflammation, and regional myocardial contractile dysfunction in the absence of coronary artery stenosis [2-6]. Recent magnetic resonance imaging (MRI) studies reported that left ventricular ejection fraction (LVEF) decreased at $6 \mathrm{~h}[7,8]$, and then recovered spontaneously one week after CME [4, 7]. Coronary flow reserve (CFR) [9-11] and coronary artery blood pressure after CME rarely have been studied, and previous animal model studies used an open-chest approach which might affect haemodynamics during model preparation. Therefore, in the present study, we assessed the magnitude and potential underlying mechanisms of changes in LVEF and CFR after CME using an animal model developed by our team.

\author{
Corresponding author: \\ Junbo Ge, MD, FESC, FACC, \\ FSCAI \\ Department of Cardiology \\ Zhongshan Hospital \\ Fudan University \\ and Shanghai Institute \\ of Cardiovascular Diseases \\ 180 Fenglin Road \\ Shanghai 200032, China \\ Phone: 86-21-64041990, \\ ext. 2745 \\ Fax: 86-21-64223006 \\ E-mail: ge.junbo@ \\ zs-hospital.sh.cn
}




\section{Material and methods}

\section{Methods}

The experimental protocols of this study were approved by the Animal Care and Use Committee of Fudan University, China. The animals were handled according to the guidelines of the American Physiological Society.

Six miniature swine of either sex (20-25 kg body weight) were initially sedated with intramuscular injection of a combination of ketamine $(5-10 \mathrm{mg} / \mathrm{kg})$ and diazepam (5-10 mg/kg). Anaesthesia was maintained with $3 \%$ pentobarbital sodium intravenously $(3 \mathrm{mg} / \mathrm{kg} / \mathrm{h})$ until the experiment was completed, and the animals were observed until awakening and spontaneously breathing without intubation was achieved. The swine were anaesthetized a second time one wake later.

\section{Study design}

Echocardiography and CFR of all the six swine studied were recorded and measured at baseline, $2 \mathrm{~h}, 6 \mathrm{~h}$ and 1 week later. Teichholtz formula was used to calculate LVEF and left ventricular volume.

\section{Coronary microembolization methodology}

The right femoral artery and vein were dissected; $7 \mathrm{~F}$ and $6 \mathrm{~F}$ vascular sheaths were placed in each vessel, respectively. Prior to coronary cannulation, animals were anticoagulated with intravenous heparin: $5000 \mathrm{IU}$ bolus followed by $100 \mathrm{IU} / \mathrm{kg} / \mathrm{h}$. For coronary angiography, a 6 F XB 3.5 guiding catheter was used for the left coronary artery system via the femoral approach, and a $2.8 \mathrm{~F}$ infusion catheter (Cordis Inc., Johnson\&Johnson) was then placed in the LAD artery between the second and third diagonal branches. Microembolization was induced by manual continuous injection of 120,000 microspheres (42 $\mu \mathrm{m}$ Dynospheres; Dyno Particles; Lillestrøm, Norway) into the LAD followed by a $6 \mathrm{ml}$ saline flush. Measurements of systemic haemodynamics and myocardial function were repeated at baseline, 2 h, 6 h and 1 week after CME. A blood sample was drawn and serum was separated for further analysis. Aortic pressure was monitored through the guiding catheter.

\section{Left ventricular ejection fraction measurement by echocardiography}

Animals were investigated in a right lateral position. Transthoracic echocardiographic studies were performed by one experienced investigator who was blinded to the study protocol using a GE VIVID 7 system with a $1.5-4.3 \mathrm{MHz}$ transducer. Two-dimensional and $\mathrm{M}$-mode imaging data were acquired using a parasternal short-axis view at the level of the papillary muscles and recorded on the videotape. Left ventricular ejection fraction, fractional shortening (FS), left ventricular end systolic (LVESV) and end diastolic (LVEDV) volumes were obtained from M-mode echocardiography.

\section{Measurement of coronary flow reserve and coronary pressure}

Coronary blood flow velocity and pressure were determined with a Doppler flow guidewire (0.014 inch, FlowWire ${ }^{\circledR} \mathrm{XT}$, Volcano) and a pressure wire (0.014 inch, SmartWire, Volcano). Coronary pressure and average peak flow velocity (APV) in the LAD were recorded at rest and at hyperaemia (18 mg adenosine). Coronary flow reserve (CFR) was calculated as the ratio of hyperaemic/baseline APV during hyperaemia.

\section{Measurement of myocardial blood flow before and after coronary microembolization}

Quantification of regional myocardial blood flow was evaluated at baseline, $2 \mathrm{~h}, 6 \mathrm{~h}$ and 1 week using four different-coloured (yellow, red, blue, violet) $15-\mu \mathrm{m}$ microspheres (E-Z Trac corporation) [12] For each measurement, $5 \times 10^{6}$ to $10 \times 10^{6}$ microspheres suspended in $6 \mathrm{ml}$ of saline with $0.02 \%$ Tween 80 (Sigma) were injected into the left ventricle followed by a $10 \mathrm{ml}$ saline flush. Withdrawal of femoral arterial reference blood samples started $10 \mathrm{~s}$ before injection of the microspheres and continued for $70 \mathrm{~s}$ at a rate of $5.4 \mathrm{ml} / \mathrm{min}$ (model DDB-300; China). After the experiment, the heart was removed and samples from the posterior and anterior wall were taken for measurement of regional blood flow. Tissue digestion, extraction of the dye, and calculation of regional myocardial blood flow were performed as described previously [12].

\section{Measurement of serum monocyte chemotactic protein-1 and endothelin-1}

Measurement of serum monocyte chemotactic protein-1 (MCP-1) and endothelin-1 (ET-1) concentration was performed using an ELISA kit from R\&D Company (USA).

\section{Postmortem analysis}

The animals were euthanized by intravenous injection of $30 \mathrm{ml}$ of $10 \%$ potassium chloride. The heart was removed and sectioned into 5 slices from apex to base in a plane parallel to the atrioventricular groove and immersed in a $0.2 \mathrm{~mol} / / \mathrm{l}$ sodium phosphate buffer ( $\mathrm{pH}$ 7.4) containing 1.0\% nitroblue tetrazolium chloride (NBT) (Sigma, Deisenhofen, Germany) for $20 \mathrm{~min}$ at $37^{\circ} \mathrm{C}$ to identify infarcted tissue. About $200 \mathrm{mg}$ transmural tissue specimens 
from the anterior walls (CME zone) and the posterior walls (control) were taken and immediately fixed in $4 \%$ buffered formaldehyde. The formaldehyde-fixed specimens were embedded in paraffin and sectioned into $5-\mu m$ thick slices. Haematoxylin and eosin (HE) staining was used to demonstrate the presence of myocardial necrosis. Inflammatory cells were counted in 10 fields of $190,000 \mu \mathrm{m}^{2}$ each from the microembolized and the control area. The vast majority of inflammatory cells were polymorphonuclear leukocytes (PMN).

\section{TUNEL assays}

Cardiomyocyte apoptosis was quantified by the TdT-mediated dNTP Nick-End Labelling (TUNEL) technique (R\&D Company, USA). Formalin-fixed sections $(5 \mu \mathrm{m})$ were treated with proteinase $\mathrm{K}$ $(20 \mu \mathrm{g} / \mathrm{ml})$ and then with $50 \mu \mathrm{l}$ of reaction mix (TdT dNTP mix $(1 \mu \mathrm{l}))$ in the presence of $50 \times \mathrm{Mn}^{2+}(1 \mu \mathrm{l})$, TdT enzyme $(1 \mu \mathrm{l})$ and $1 \times \mathrm{TdT}$ Labeling Buffer $(50 \mu \mathrm{l})$ at $37^{\circ} \mathrm{C}$. In each specimen, TUNEL-positive cardiomyocyte nuclei were counted in 40 random highpower fields $(400 \times)$, and the percentage ratio of TUNEL-positive cell nuclei to the total number of cell nuclei was calculated.

\section{Statistical analysis}

Data are reported as mean \pm standard deviation (SD). Changes of haemodynamics, coronary flow reserve, coronary pressure, average peak flow velocity at rest and hyperaemic and myocardial function were compared using a general linear model of variance for repeated measures with SPSS 11.0 software. A $p$ value of $<0.05$ was considered statistically significant.

\section{Results}

As shown in Table I, systemic haemodynamics remained stable throughout the experiment. Coronary angiography showed that TIMI 3 flow was maintained immediately after CME.

\section{Left ventricle size measured by echocardiography}

After CME, LVEF progressively decreased at $2 \mathrm{~h}$ and $6 \mathrm{~h}$, and returned to baseline at 1 week. The LVESV enlarged over time, with the difference achieving statistical significance relative to baseline at $2 \mathrm{~h}(p<0.05)$, and the enlargement persisting from $6 \mathrm{~h}$ to one week after CME ( $6 \mathrm{~h}$ vs. baseline $p<0.05 ; 1$ week vs. baseline $p<0.01)$. However, LVEDV only was significantly increased vs. baseline 1 week $(p<0.01)$ after CME. The latter observations suggest that LV dilation is continued from $6 \mathrm{~h}$ to 1 week after CME despite LVEF recovery (Figures 1 and 2).

\section{Changes of coronary flow reserve and pressure}

Average base peak velocity did not differ throughout the study. Average coronary hyperaemic peak velocity significantly decreased from 16.80 $\pm 4.30 \mathrm{~cm} / \mathrm{s}$ at baseline to $12.30 \pm 2.60 \mathrm{~cm} / \mathrm{s}$ at $2 \mathrm{~h}$ ( $p<0.05)$; a further decrease in velocity was observed at $6 \mathrm{~h}(16.80 \pm 4.30 \mathrm{~cm} / \mathrm{s}$ at baseline vs. $10.20 \pm 1.90 \mathrm{~cm} / \mathrm{s}$ at $6 \mathrm{~h}, p<0.01)$. The CFR only was significantly reduced at $6 \mathrm{~h}(1.24 \pm 0.10$ at $6 \mathrm{~h}$ vs. $1.77 \pm 0.30$ at baseline, $p<0.01)$. Coronary pressure did not differ before and after CME, both at baseline and hyperaemia (Table II).

\section{Changes of myocardial blood flow}

Anterior subendocardial blood flow (ASBF) was $1.3 \pm 0.2 \mathrm{ml} / \mathrm{min} \times \mathrm{g}$ at baseline, $1.4 \pm 0.2 \mathrm{ml} / \mathrm{min} \times \mathrm{g}$ at $2 \mathrm{~h}, 1.1 \pm 0.2 \mathrm{ml} / \mathrm{min} \times \mathrm{g}$ at $6 \mathrm{~h}$ and $1.3 \pm 0.3 \mathrm{ml} /$ min $\times \mathrm{g}$ at 1 week after CME; posterior subendocardial blood flow (PSBF) was $1.4 \pm 0.2 \mathrm{ml} / \mathrm{min} \times \mathrm{g}$ at baseline, $1.3 \pm 0.2 \mathrm{ml} / \mathrm{min} \times \mathrm{g}$ at $2 \mathrm{~h}, 1.2 \pm 0.1 \mathrm{ml}$ $\min \times g$ at $6 \mathrm{~h}$ and $1.2 \pm 0.2 \mathrm{ml} / \mathrm{min} \times \mathrm{g}$ at 1 week after CME. The ratio of ASBF to PSBF was $0.9 \pm 0.1$ at baseline, $1.0 \pm 0.1$ at $2 \mathrm{~h}, 1.1 \pm 0.3$ at $6 \mathrm{~h}$ and 1.1 \pm 0.3 at 1 week after CME (Figure 3). Although the ratio of ASBF to PSBF slightly increased after CME, there was no statistically significant difference for

Table I. Changes in systemic haemodynamics and parameters before and after CME

\begin{tabular}{|lcccc|}
\hline Parameter & Base & $2 \mathrm{~h}$ & $6 \mathrm{~h}$ & 1 week \\
\hline HR $[\mathrm{bpm}]$ & $113.0 \pm 12.6$ & $127.5 \pm 9.2$ & $121.0 \pm 13.5$ & $119.0 \pm 8.0$ \\
\hline SBP $[\mathrm{mmHg}]$ & $134 \pm 5.4$ & $134.3 \pm 5.3$ & $128.7 \pm 10.5$ & $129.1 \pm 7.3$ \\
\hline DBP $[\mathrm{mmHg}]$ & $100.1 \pm 9.5$ & $97.1 \pm 9.3$ & $92.5 \pm 11.3$ & $95.8 \pm 6.6$ \\
\hline LVESV $[\mathrm{ml}]$ & $11.7 \pm 5.4$ & $18.5 \pm 6.4$ & $19.2 \pm 4.5$ & $22.1 \pm 8.9$ \\
\hline LVEDV $[\mathrm{ml}]$ & $50.6 \pm 10.2$ & $55.1 \pm 10.1$ & $59.5 \pm 9.2$ & $70.7 \pm 14.6$ \\
\hline LVEF & $77.0 \pm 7.6$ & $69.4 \pm 8.3$ & $67.5 \pm 8.1$ & $76.0 \pm 5.9$ \\
\hline FS & $44.6 \pm 7.8$ & $39.0 \pm 7.1$ & $37.2 \pm 6.5$ & $44.0 \pm 4.9$ \\
\hline ET-1 $[\mathrm{pg} / \mathrm{ml}]$ & $123.0 \pm 15.3$ & $138.5 \pm 8.2$ & $140.9 \pm 14.8$ & $119.0 \pm 15.6$ \\
\hline MCP-1 $[\mathrm{pg} / \mathrm{ml}]$ & $34.6 \pm 2.7$ & $41.2 \pm 2.9$ & $43.0 \pm 3.5$ & $34.9 \pm 3.5$ \\
\hline
\end{tabular}




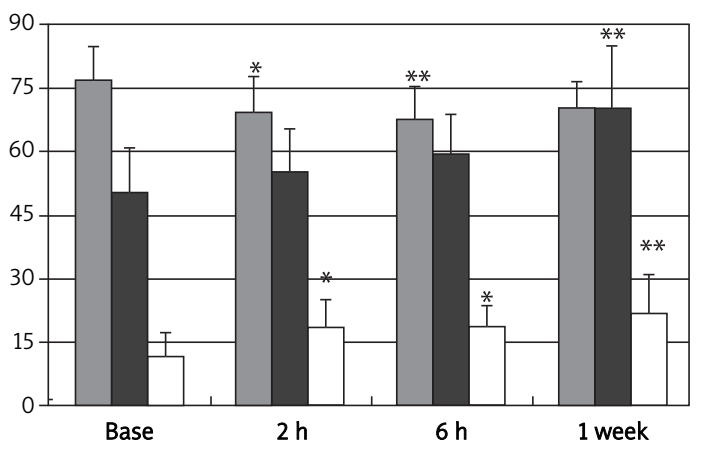

$\square \operatorname{LVEDV}[\mathrm{ml}] \quad \square \operatorname{LVESV}[\mathrm{ml}] \quad \square \operatorname{LVEF}[\%]$

Figure 1. Changes in LVEF, LVEDV and LVESV before and after CME measured by echocardiography ${ }^{*}$ vs. base $p<0.05,{ }^{* *} v$ s. base $p<0.01$

ASBF, PSBF and the ratio of ASBF to PSBF throughout the study (Figure 3).

\section{Changes of serum monocyte chemotactic protein-1 and endothelin-1}

Serum MCP-1 level significantly increased $2 \mathrm{~h}$ after CME ( $2 \mathrm{~h}$ vs. baseline $p<0.05$ ), and a further elevation was observed $6 \mathrm{~h}$ after CME ( $6 \mathrm{~h}$ vs. baseline $p<0.01)$. Serum ET-1 level was significantly elevated $6 \mathrm{~h}$ after CME ( $6 \mathrm{~h}$ vs. baseline $p<0.05$ ). However, no elevation of serum MCP-1 and ET-1 levels was observed 1 week after CME $(p>0.05$ vs.


Figure 2. Changes in left ventricular function before and after CME. A - Base, B - 2 h after CME, C - 6 h after CME, D - 1 week after CME

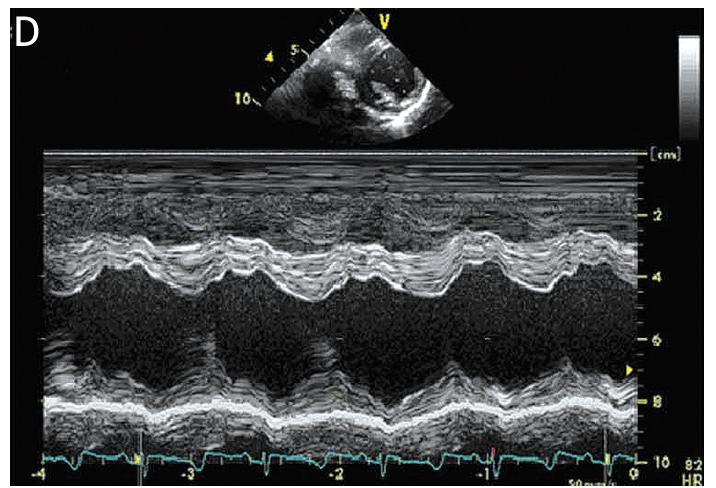

baseline). Correlation of serum MCP-1 level and LVEF was not observed in the acute phase or throughout the study; this also was true for serum ET-1 level and LVEF.

\section{Postmortem analysis}

In the postmortem analysis, microspheres and microinfarcts were detected with HE staining at the anterior myocardial wall. There was a significantly increased inflammatory response in the microembolized myocardium versus the remote myocardium (leukocytes: $542.1 \pm 260 / \mathrm{mm}^{2}$ vs. $231.1 \pm 126.3 / \mathrm{mm}^{2}$, $p<0.05)$. Microspheres were surrounded by a layer of endothelium (Figure 4). As shown in the TUNEL assay results in Figure 4, the percentage of apoptotic cardiomyocytes in the anterior myocardium at 1 week $(8.13 \pm 0.99 \%)$ after CME was significantly higher than that of inferior myocardium (0.12 $\pm 0.07 \%, p<0.01$ ) (Figure 4). Infarction was not observed with NBT staining in the short axis sections.

\section{Discussion}

The present study shows that, after CME, CFR decreased significantly at $6 \mathrm{~h}$ and recovered at 1 week, while LVEF continued to decrease from $2 \mathrm{~h}$ to $6 \mathrm{~h}$ and recovered at 1 week.

Coronary microembolization is a frequent phenomenon in patients undergoing $\mathrm{PCl}$, especially in those with acute coronary syndrome (ACS). Rup- 
Table II. Changes in CFR, coronary flow velocity and coronary pressure after CME

\begin{tabular}{|lcccc|}
\hline Parameter & Baseline & $\mathbf{2 ~}$ & $6 \mathrm{~h}$ & 1 week \\
\hline Heart rate $[\mathrm{bmp}]$ & $112.4 \pm 12.9$ & $104.8 \pm 26.4$ & $115.0 \pm 12.2$ & $113.3 \pm 2.9$ \\
\hline Average base peak velocity $[\mathrm{cm} / \mathrm{s}]$ & $8.0 \pm 1.1$ & $9.2 \pm 1.5$ & $8.8 \pm 1.3$ & $9.7 \pm 1.2$ \\
\hline Average hyperaemic peak velocity $[\mathrm{cm} / \mathrm{s}]$ & $16.8 \pm 4.3$ & $12.3 \pm 2.60$ & $10.2 \pm 1.90$ & $15.0 \pm 3.0$ \\
\hline Coronary flow reserve $(\mathrm{CFR})$ & $1.8 \pm 0.3$ & $1.7 \pm 0.1$ & $1.2 \pm 0.1$ & $1.6 \pm 0.2$ \\
\hline Average base coronary pressure $[\mathrm{mmHg}]$ & $115.5 \pm 39.2$ & $114.7 \pm 53.3$ & $88.5 \pm 25.8$ & $116.0 \pm 34.9$ \\
\hline Average hyperaemic coronary pressure $[\mathrm{mmHg}]$ & $112.5 \pm 38.0$ & $107.7 \pm 25.9$ & $88.7 \pm 26.9$ & $110.3 \pm 32.8$ \\
\hline
\end{tabular}

ture of atherosclerotic plaque in an epicardial coronary artery is believed to be the main cause of CME [13]. Previous studies have shown that CME causes a transient decrease of coronary blood flow followed by reactive hyperaemia [14]; the latter is due to the release of adenosine from endothelial cells after CME [14]. In the present study, microembolization induced a reduction of coronary average hyperaemic peak velocity at $2 \mathrm{~h}$, with a further significant reduction at $6 \mathrm{~h}$, followed by recovery at 1 week after CME. Coronary average base peak velocity slightly increased $2 \mathrm{~h}$ after CME and continued to increase even 1 week after CME. Reduction of CFR was observed at $6 \mathrm{~h}$ after CME. The changes of CFR and
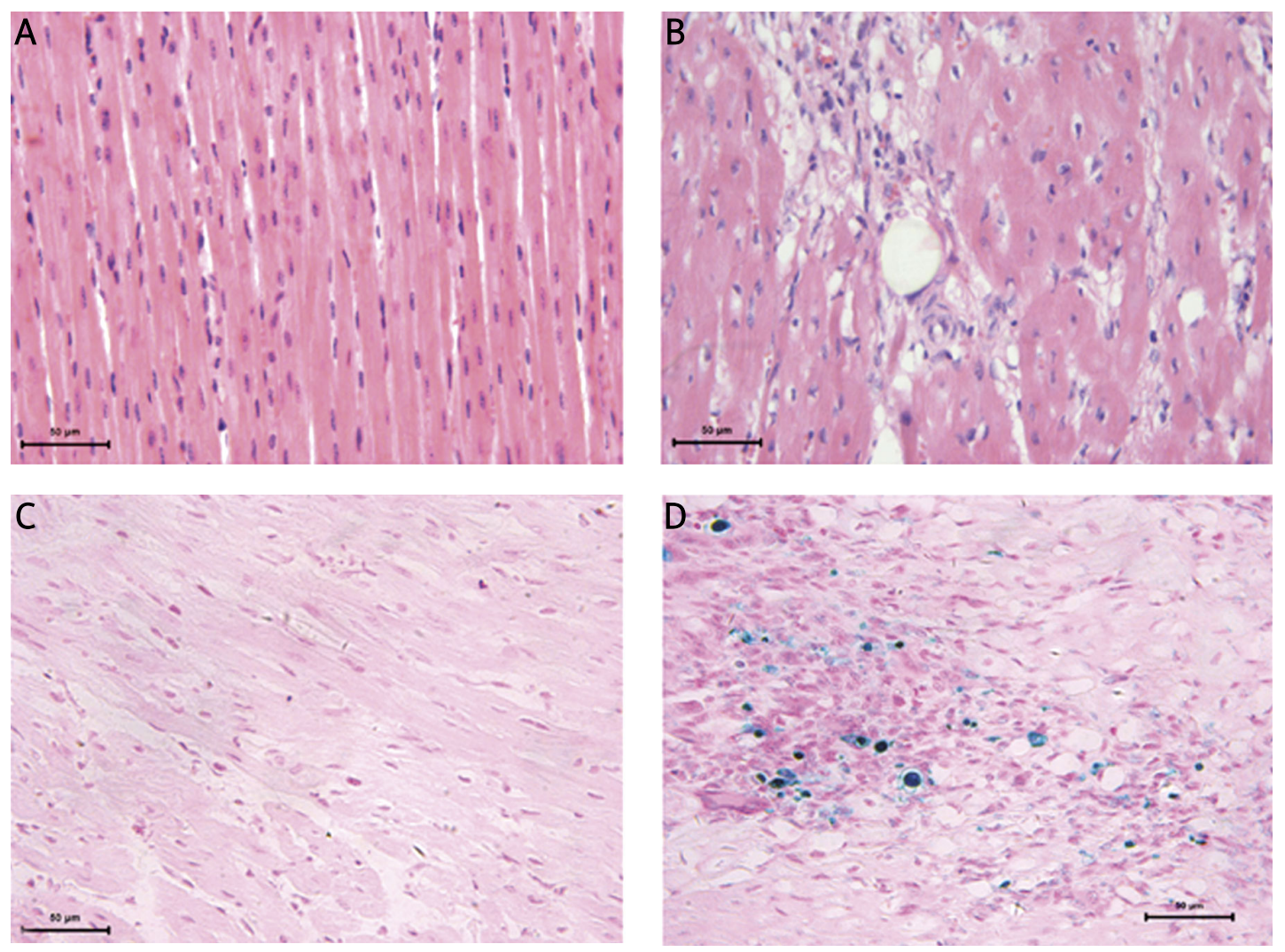

Figure 4. HE staining of myocardium and apoptosis before and after CME (400x). A - Posterior myocardium after CME. B - Anterior myocardium after CME. Microsphere is at the middle. The microsphere is surrounded by inflammation and infarction. C - Posterior myocardium after CME. No apoptosis is observed. D - Anterior myocardium after CME. Blue nuclear indicates apoptosis after CME 
hyperaemic velocity may be related to changes in endothelial function after CME, as reflected by changes in serum ET-1 levels after microembolization. Endothelin-1 is a potent vasoconstrictor that is mainly synthesized by the endothelium [15]; its vasoconstriction effect is mainly on the microvasculature [16]. Thus, ET-1 released from the local endothelium might lead to sustained microvascular constriction of the coronary artery [17]. Endothelin-1 can also enhance endothelium permeability and cause oedema which might induce compression of small arteries [18]. Furthermore, ET-1 is proven to be an important modulator of leukocytes [19], by stimulating accumulation of polymorphonuclear (PMN) leukocytes and their adhesion to the endothelium [19], which might account for microvascular dysfunction. Recent studies by Niccoli et al. also showed that ET-1 levels were elevated in patients with a first event of acute myocardial infarction undergoing successful primary or rescue $\mathrm{PCI}$ with no reflow [20], and that plasma ET-1 level is able to predict angiographic no-reflow after successful primary or rescue $\mathrm{PCl}$. In this study, serum ET-1 level was significantly elevated at $6 \mathrm{~h}$ after CME, which indicates that endothelial dysfunction occurs in the acute phase, as reflected by reduction of CFR. One week later, elevation of serum ET-1 level was no longer observed, indicating recovery of endothelial function as a result of CFR recovery. Although changes in CFR were demonstrated after CME, myocardial blood flow remained unaltered throughout the study. This might be due to the dilation and hyperaemic response of small vessels without microembolization as a consequence of adenosine released from the endothelium after CME [14].

In animal studies, repeated CME without coronary stenosis induces regional contractile dysfunction without influencing regional myocardial blood flow [2]. In a sheep model, chronic, severe, ischaemic heart failure was reported following repeated CME. The LVEDV increased $73 \%$ with the induction of heart failure and remained $55 \%$ above baseline; left ventricular end diastolic diameter showed a stable $30 \%$ increase, and a stable thinning of the LV wall was observed. It has been demonstrated that repeated CME leads to left ventricular remodelling lasting for at least 6 months [21]. Our previous study using MRI indicated that LVEF decreased at $6 \mathrm{~h}$ and recovered 1 week later in concert with persistent dilation of the left ventricle [7]. In the present study, we demonstrated that LVEF decreased in the acute phase after CME and then recovered 1 week later, with a persistent increase of left ventricular systolic and diastolic volumes. This observation suggests that left ventricular remodelling after $\mathrm{CME}$ continues despite cardiac function recovery 1 week later.
In the present study, LVEF decreased at $2 \mathrm{~h}$ after CME, which might be due to the inflammatory reaction after microinfarcts rather than apoptosis [22]. The inflammatory reaction observed in the present study is characterized by infiltration of PMN in the embolized zone and elevation of serum MCP-1 levels $6 \mathrm{~h}$ after CME. We propose that the mechanism by which left ventricular dilation with preserved LVEF develops 1 week later relates to neurohumoral activation and the inflammatory response after CME $[21,23]$. A previous study demonstrated that a small amount of myocardial injury can lead to neurohumoral activation with elevation of plasma angiotensin II and norepinephrine levels [23]. Neurohumoral activation may lead to multiple effects, including renal salt and water retention which increase intravascular volume $[23,24]$, resulting in elevation of left ventricular end-diastolic volume and subsequently left ventricular end-diastolic pressure. The present study also showed that the inflammatory reaction was significantly greater in the embolized zone than in the control zone. The infiltration of leukocytes in the embolized zone suggests a role of tumour necrosis factor $\alpha[5,25]$ and oxygen free radicals in the progression of left ventricular remodelling $[26,27]$. Furthermore, in the present study, focal ischaemia and necrosis were observed in the embolized zone, although infarction was not demonstrated using NBT staining. The ischaemia and necrosis may be greater than that in the control zone [2]. Those factors acting together may ultimately result in left ventricular remodelling.

A recent study evaluating the changes after CME measured by magnetic resonance imaging showed a significant decline in LVEF not only $1 \mathrm{~h}$ after injection, but also 1 week after injection [28]. Differences between microspheres used in the animal models may account for the differing results with the current study. Larger diameter microspheres might induce a persistent decline in LVEF.

One of the limitations of this study was that only a few swine were investigated. However, the statistical power for the current sample was adequate to demonstrate a difference in CFR and LVEF before and after CME. A second limitation is the lack of control groups. Therefore, it cannot be excluded that changes in CFR and LVEF are casual. However, previous studies have demonstrated that changes seen in this type of animal model resemble those reported in patients with CME. Thirdly, this animal model resembles but does not exactly replicate conditions seen in $\mathrm{PCl}$ in which diameters of thromboemboli are frequently much larger and varied, and sometimes do not cause myocardial damage. Besides these limitations, a prolonged observation period would be warranted to determine the longterm effects of CME on left ventricular remodelling, 
and further studies are needed to explore the effects of an antagonist of serum ET-1 on CFR as well as left ventricular remodelling.

In conclusion, left ventricular dilation with preserved LVEF and CFR was observed after CME. This observation could be of significance for clinical management of CME in the future.

\section{Acknowledgments}

Jianying Ma and Juying Qian contributed equally to the paper. We gratefully acknowledge Dr. William Kongto Hau for critically reviewing the manuscript. This study was supported by the National Natural Science Foundation of China (No. 30901383).

\section{References}

1. Heusch G, Kleinbongard P, Böse D, et al. Coronary microembolization: from bedside to bench and back to bedside. Circulation 2009; 120: 1822-36.

2. Dörge $H$, Neumann T, Behrends $M$, et al. Perfusioncontraction mismatch with coronary microvascular obstruction: role of inflammation. Am J Physiol Heart Circ Physiol 2000; 279: H2587-92.

3. Thielmann M, Dörge $H$, Martin C, et al. Myocardial dysfunction with coronary microembolization: signal transduction through a sequence of nitric oxide, tumor necrosis factor-alpha and sphingosine. Circ Res 2002; 90 : 807-13.

4. Skyschally A, Haude M, Dörge $H$, et al. Glucocorticoid treatment prevents progressive myocardial dysfunction resulting from experimental coronary microembolization. Circulation 2004; 109: 2337-42.

5. Dörge H, Schulz R, Belosjorow $S$, et al. Coronary microembolization: the role of TNF-alpha in contractile dysfunction. J Mol Cell Cardiol 2002; 34: 51-62.

6. Heusch P, Skyschally A, Leineweber K, Haude M, Erbel R, Heusch $G$. The interaction of coronary microembolization and ischemic preconditioning: A third window of cardioprotection through TNF-alpha. Arch Med Sci 2007; 3: 83-92.

7. Ma J, Qian J, Jin H, et al. Acute hyperenhancement on delayed contrast-enhanced magnetic resonance imaging is the characteristic sign after coronary microembolization. Chin Med J 2009; 122: 687-91.

8. Breuckmann F, Nassenstein K, Bucher C, et al. Systematic analysis of functional and structural changes after coronary microembolization: a cardiac magnetic resonance imaging study. JACC Cardiovasc Imaging 2009; 2: 121-30.

9. Skyschally A, Schulz R, Erbel R, Heusch G. Reduced coronary and inotropic reserves with coronary microembolization. Am J Physiol Heart Circ Physiol 2002; 282: H611-4.

10. Herrmann J, Haude M, Lerman A, et al. Abnormal coronary flow velocity reserve after coronary intervention is associated with cardiac marker elevation. Circulation 2001; 103: 2339-45.

11. Bahrmann P, Werner GS, Heusch G, et al. Detection of coronary microembolization by Doppler ultrasound in patients with stable angina pectoris undergoing elective percutaneous coronary interventions. Circulation 2007; 115: 600-8.
12. Kowallik, P, Schulz R, Guth BD, et al. Measurement of regional myocardial blood flow with multiple colored microspheres. Circulation 1991; 83: 974-82.

13. Davies MJ, Thomas AC. Plaque fissuring - the cause of acute myocardial infarction, sudden ischaemic death, and crescendo angina. Br Heart J 1985; 53: 363-73.

14. Hori M, Inoue $M$, Kitakaze $M$, et al. Role of adenosine in hyperemic response of coronary blood flow in microembolization. Am J Physiol 1986; 250: H509-18.

15. Yanagisawa M, Kurihara $\mathrm{H}$, Kimura S, et al. A novel potent vasoconstrictor peptide produced by vascular endothelial cells. Nature 1988; 332: 411-5.

16. Brain SD, Tippins JR, Williams TJ. Endothelin induces potent microvascular constriction. Br J Pharmacol 1988; 95: 1005-7.

17. Velasco CE, Turner $M$, Inagami $T$, et al. Reperfusion enhances the local release of endothelin after regional myocardial ischemia. Am Heart J 1994; 128: 441-51.

18. Filep JG, Földes-Filep E, Rousseau A, Fournier A, Sirois P, Yano $M$. Endothelin-1 enhances vascular permeability in the rat heart through the ETA receptor. Eur J Pharmacol 1992; 219: 343-4.

19. López Farré A, Riesco A, Espinosa G, et al. Effect of endothelin-1 on neutrophil adhesion to endothelial cells and perfused heart. Circulation 1993; 88: 1166-71.

20. Niccoli G, Lanza GA, Shaw S, et al. Endothelin-1 and acute myocardial infarction: a no-reflow mediator after successful percutaneous myocardial revascularization. Eur Heart J 2006; 27: 1793-8.

21. Huang Y, Hunyor SN, Jiang L, et al. Remodeling of the chronic severely failing ischemic sheep heart after coronary microembolization: functional, energetic, structural, and cellular responses. Am J Physiol Heart Circ Physiol 2004; 286: H2141-50.

22. Heusch G, Kleinbongard P, Böse D, et al. Coronary microembolization: from bedside to bench and back to bedside. Circulation 2009; 120: 1822-36.

23. He KL, Dickstein M, Sabbah HN, et al. Mechanisms of heart failure with well preserved ejection fraction in dogs following limited coronary microembolization. Cardiovasc Res 2004; 64: 72-83.

24. Schrier RW, Abraham WT. Hormones and hemodynamics in heart failure. N Engl J Med 1999; 341: 577-85.

25. Irwin MW, Mak S, Mann DL, et al. Tissue expression and immunolocalization of tumor necrosis factor-alpha in postinfarction dysfunctional myocardium. Circulation 1999; 99: 1492-8.

26. Hori M, Gotoh K, Kitakaze M, et al. Role of oxygen-derived free radicals in myocardial edema and ischemia in coronary microvascular embolization. Circulation 1991; 84: 828-40.

27. Canton M, Skyschally A, Menabò R, et al. Oxidative modification of tropomyosin and myocardial dysfunction following coronary microembolization. Eur Heart J 2006; 27: 875-81.

28. Carlsson M, Wilson M, Martin AJ, Saeed M. Myocardial microinfarction after coronary microembolization in swine: MR imaging characterization. Radiology 2009; 250: 703-13. 